folk/ed. Derg, 2020; 26(4):-951-970

DOI: $10.22559 /$ folklor.1247

\title{
1940'larda Bir Moda Düşkünlüğünün Türk Edebiyatına Yansımaları: Bobstil Moda ve Bobstil Edebiyat
}

\author{
The Impact of a Fashion Trend on Turkish Literature \\ in the 1940s: \\ Bobstil Fashion Trend and Bobstil Litarature
}

İbrahim Özen*

\begin{abstract}
$\ddot{\mathbf{O z}}$
Bobstil, 1940'lı yıllara damga vuran züppece giyim tarzını ve bu giyim tarzını benimseyen tipleri karşılayan kelimedir. Türkiye'de sinemanın yaygınlaşmasından sonra bilhassa büyükşehirlerdeki gençlerin Hollywood aktörlerini kıyafet, tavır ve davranış bakımından taklit etmeleriyle ortaya çıkmıştır. Bu çalışmanın amacı, bobstil modanın ayırıcı özelliklerini belirlemek, bobstilleri sosyal hayattaki rolleri ve edebiyata yansımalarıyla incelemektir.

Çalışmanın başlıca kaynakları, devrin süreli yayınlarında yer alan züppelik anlatısına ve bobstil modaya dair köşe yazıları ile edebî metinlerdir. Yapılan tasnif ve değerlendirmeler neticesinde, öncelikle bobstil modanın kaynağı, Tanzimat’tan itibaren züppe tipine yönelik giyim üzerinden yapılan yakıştırmalar, bobstillerin dış görünüşleri ve duygu dünyaları açıklanmıştır. Daha sonra, bobstilin hem kavram hem de tip manasıyla edebiyata nasıl tezahür ettiği üzerinde durulmuştur.
\end{abstract}

Geliş tarihi (Received): 23.04.2020- Kabul tarihi (Accepted): 12.09.2020

Dr. Öğr. Üyesi. İstanbul Sabahattin Zaim Üniversitesi İnsan ve Toplum Bilimleri Fakültesi Türk Dili ve Edebiyatı Bölümü. i.ozen@hotmail.com. ORCID 0000-0001-7707-5252 
Çalışma sonucunda, bobstilin sosyal hayattan edebiyata uzanan tesirleri ortaya çıkarılmıştır: 1940'lı yıllardaki edebiyat tartışmalarında geleneği reddedip yeni eserlerle ortaya çıkan şairler "bobstil şair", garip karşılanan şiirleri ise "bobstil şiir” yakıştırmasına uğramıştır. Kurmaca metinlerde iki tip bobstille karşılaşıılmıştır. Bunlardan ilki sanatla ilgilenen, âhenk ve manadan yoksun şiirler kaleme alan bobstil şairlerdir. Diğeri ise dış görünümü ve iç dünyası ile dejenere bir yapıya sahip olan toplumdaki züppe gençlerdir. Çalışma, moda-edebiyat ilişkisine dikkat çekmesi ve alafranga züppe tipinin yeni görünümünü tespiti bakımından edebiyat tarihine katkı sağlayacaktır.

Anahtar sözcükler: moda, züppe, bobstil edebiyat, bobstil şiir, bobstil tip

\begin{abstract}
Bobstyle is the term that represents the dandyish dressing style in the 1940s and those who adopt this dressing style. As a fashion cycle of the pervasion of cinema in Turkey, it emerged when young people in metropolitan cities imitated Hollywood actors in terms of clothing, attitude and behavior. The aim of this study is to define the distinctive features of the bobstyle fashion, to examine bobstyles with their roles in social life and their reflections on literature.

The main sources of the study are literary texts and the editorial narration in the periodical publications of the period and the opinion columns about bobstyle fashion. As a result of the classification and analyses, firstly, the source of the bobstyle fashion, the accusations made over the snob type from the Tanzimat, the exterior appearance of the bobstyles and the emotional worlds were explained. Then, it is highlighted how bobstyle is manifested to literature in terms of both concept and type.

The findings from the study revealed the effects of bobstyle from social life to literature. In the literature discussions in the 1940s, the poets who rejected the tradition and emerged with new works were called "bobstyle poet", the strange welcoming poems were called "bobstyle poetry." In fictional texts, two types of bobstyles were encountered. First is the bobstyle poets who are interested in art and who write poems that are devoid of meaning. Second is the young snob who has a degenerated nature with his physical appearance and inner word. The study will contribute to the history of literature in terms of highlighting the relationship between fashion and literature and determining the new look of the European snob type.
\end{abstract}

Keywords: fashion, dandy, bobstyle literature, bobstyle poet, bobstyle type

\title{
Extended summary
}

Bobstil is a clothing fashion resulting from the imitating of Hollywood actors in American cinema after the expansion of cinema in Turkey. Influencing especially the young people in metropolitan cities through clothing firstly, bobstil has also been used as a word referring to dandy people after transforming into a lifestyle. As in the ascribing of the words didon, monsieur, tango, charleston for the dandyies types, bobstil has been used for all kinds of innovation, difference and foreignness. 
The purpose of this study is to determine the characteristics of bobstil fashion and to examine how it has affected literature through social life. At the same time, it is to reveal the change of the appearance of snob type in the line from the Ottoman to the Republic depending on the culture affected. The sources of the study are the articles depicting snob and bobstil fashion in the 1940s when the bobstil fashion was on the agenda.

What makes Bobstil type prominent in terms of being an outfit fashion is the outer view. They have long, brilliantine-applied hair, colorful and long-collar shirts, loose and stoopshouldered jackets, tight-fitting short trousers, straps which they use instead of belts, and oversized shoes. Bobstils walk with their breasts tucked in, hunching their backs, waving their arms forward, and always with their hands in the pockets of their trousers. One of the sine qua non about their appearance is the pipes they carry constantly in their mouths.

There were also bobstil women as well as bobstil men in Turkey in the 1940's. They attract attention with their broad-brimmed hats, short skirts, colorful and roughly stitched socks, high sole shoes, painted lips, flamboyant earrings, fingers with large rings. Bobstil women aimed to follow the fashion of the period like the bobstil men. Apart from their clothes, they were identical with bobstil men with their speech, behavior and inner world.

Bobstils often call each other "excellency". It is customary for them to prefer slang words, to speak English words in unusual places. The music style they listen to is swing music, which is the product of the culture they are influenced by. They live consumption-oriented because they put entertainment at the center of life. They always need their families because they don't work or produce. Bobstils are also degenerate types that have been alienated from the society they live in and disregard national and spiritual values.

It is possible to review the relation of Bobstil fashion with literature under three headings. The first of these is that Bobstil is a word used in the literature discussions of the 1940s with its meaning expansion that includes all kinds of innovation and difference. Orhan Veli, Oktay Rifat and Melih Cevdet, who formed the Garip Movement, were subjected to the term "bobstil poet" by those who defended the traditional poetry of the period. Their poems, which were seen as unharmonious and meaningless, were similarly criticized as "bobstil poetry". The verse "Yazık oldu Süleyman Efendiye! .." of Orhan Veli's poem titled "Kitabe-i Seng-i Mezar", was the subject of discussion until the end of 1940s. Asaf Halet Çelebi was one of the poets who have been subjected to be called bobstil with his clothing style and poems that make difference for his period. His verses "Om mani padme hum" in the poem "Sidharta" were made a mockery. Apart from these, bobstil has also penetrated into the language of poetry with the meaning of the fashion-loving dandy youth of the period.

Two other titles that make up the relation of bobstil fashion with literature are related to bobstil types in literary texts. The first of these is the poets who follow the bobstil fashion and engage in art. The prominent feature of this type is the rejection of past poets and the current language of poetry and the search for new ones, their desire to create a new poetry movement, and that their poems are seen as absurd and meaningless. A novel, theater text, poetry and two short stories for poetry type were identified. All of the texts mentioned were published in the 
early years of the 1940s. Therefore, it can be said that these texts were written beyond the humor for the purpose of criticizing the Turkish poets and new poems of the period.

Another bobstil type clothes in literary texts are society's dandy youth with their unawareness of national and spiritual values. The distinctive characteristics of them are that they see life as entertainment, live unconsciously, and do not appreciate love. Two short texts that were published as a book to determine this type and stories published in daily newspapers have been reached. The critical attitudes of story writers towards bobstils should be evaluated in the same frame as the columns in newspapers. The fact that it poses a danger to the Republic's revolution generation with its body and mind should be seen as the main reason for targeting bobstyles.

In conclusion, the sources of the bobstil fashion which marked highly Turkey in the 1940s and the general characteristics of bobstils and Turkey have been identified. At the same time, the inclusion of a fashion trend that influenced social life and the type it created included in literature debates and literary texts have been discussed. It is possible to say the following conclusion about the bobstils in literary texts: Bobstil is similar to the prominent examples of false Westernization, such as Bihruz Bey in the Araba Sevdasi of Tanzimat and Meftun Bey in the novel Şıpsevdi. In other words, bobstil is a new appearance of the European dandy type changed according to the conditions of the time, with its dressing, speech, behavior, alienation from its own culture and history. Depending on the imitated civilization, the dandy, which turned to French culture and language in the past, turned to American culture and English with the influence of Hollywood cinema in the 1940s.

\section{Giriş}

Türkiye, 1930'lu yılların sonlarında tanınıp 1940'larda bilhassa büyükşehirlerde genç nesli etkisi altına alan bobstil moda ile karşı karşıyadır. Önce kılık kıyafet üzerinden tesir eden bobstil moda, zaman içinde bir yaşam biçimine dönüşerek züppeliğin yeni bir görünümü hâline gelir. Bu moda tarzının kaynağı, sokağa ve edebiyata yansıması noktasında dönemin basınında yer alan yayınları incelemek gerekir. Ulusal-yerel gazeteler, edebiyatsanat-mizah dergileri haber, fikra ve karikatürler ile bobstil modanın kaynağını sorgulamaya, özelliklerini belirlemeye, sokağın bobstil tiplerini mizahî bir anlatımla topluma aktarmaya çalışmıştır.

Öncelikle "bobstil nedir?” diye sorgulandığ 1 takdirde birbirini tamamlayan iki mana ile karşılaşmak mümkündür. Bunlardan biri özentili ve züppece giyiniş tarzı; diğeri ise bu tarzda giyinen züppe kimsedir (Çağbayır, 2017: 775). Hem moda tarzına hem de bu moda tarzının ortaya çıkardığı tipe karşılık gelen bobstili Türkiye'nin gündemine taşıyan ilk isim Vâlâ Nureddin'dir. Onun tanımlamasına göre "bob” kelimesi, “Amerikanvarî bir küçültme ve okşama" ismi, "still" de üslup manasını taşır. Bobstil ise "Bobl tarzında giyinen delikanlı[dır]" (Nureddin, 6 Temmuz 1940: 3). Faruk Femik, bobstil modanın “Amerika'nın ileri gelen moda muhitlerinden" alındığını, kaynağının ise sinema artisti Robert Taylor olduğunu dile getirir (Femik, 18 Aralık 1940: 3). Nusret Safa Coşkun, bobstil bir gençle yaptığı röportajda, 
Vâlâ Nureddin ve Faruk Femik'in açıklamalarını desteleyecek içerikte şu bilgiye ulaşır: "Bu moda Amerika'dan geldiğinden kinaye bu isim konmuş olacak. Robert Taylor'un küçük ismi olduğu için konmuştur belki de... Çünkü Hollywood'da Robert Taylor'u 'Bob' diye çağırırlar. Aşağı yukarı orada herkesin küçük ismi 'Bob'dur” (Coşkun, 15 Birinciteşrin 1940: 7). Anlaşılacağı üzere bobstil moda, Türkiye'de sinemanın yaygınlaşmasından sonra Amerikan sinemasındaki Hollywood aktörlerinin bilhassa Robert Taylor'un kıyafetlerinin, tavır ve davranışlarının taklidiyle ortaya çıkmıştır.

Bobstil modayı ve ortaya çıkardığı tipi gelenekle ilişkilendirme noktasında, Levent Cantek'in alıntılanan tespiti yol gösterici konumdadır: "Yüzyıl başlarında ülke gerçeklerinden, sorunlarından bihaber yaşayan 'aslını inkâr eden haramzade'nin kimi zaman ironik kimi zaman da öfkeyle anlatılan, çoğunlukla 'Bihruz Bey' tiplemesiyle isimlendirilen eleştirinin yeni bir yorumudur, Bobstil” (Haziran 2001: 59). Dolayısıyla bobstil modayı takip eden tip, Tanzimat romanında yanlış batılılaşmanın belirgin bir örneği olan Recaizade Mahmut Ekrem'in Araba Sevdası'ndaki Bihruz Bey tipinin zamanın şartlarına göre evirilerek yeni bir biçimde toplum karşısına çıkmış hâlidir. Halide Edip Adıvar, Hüseyin Rahmi Gürpınar'ın eserleri üzerine kaleme aldığı yazısında, Şıpsevdi romanındaki yanlış batılılaşmanın timsali olan Meftun Bey’e dair benzer bir tespitte bulunur; dönemin bobstil tipini, "1942 yılının Meftun Bey'i'” olarak nitelendirir (12 Nisan 1944: 3).

Bobstil tip, Bihruz Bey ve Meftun Bey örneklerine bağlı olarak züppelik çerçevesinde değerlendirilmelidir. Osmanlı Devleti’nde Batılılaşma sürecinin başlaması neticesinde Tanzimat'tan sonra beliren ve romanlarda değerlendirilen züppe tipi, içinde yaşadığı toplumdan farklı olabilmenin mücadelesini vermiştir. Lakin bu mücadeleyi fikrî bir muhasebeden yoksun olarak sadece giyinişiyle, konuşmasıyla, arzularıyla, özlem ve tutkularıyla göstermeye çalışmıştır. Züppe tipinin en önemli vasıflarından biri "gibi” ve "mış" gibi davranarak özenti bir hayat tercih etmesidir. Diğeri ise "ötekine öykündüğü için kendi toplumuna ve cemaatine yabancılaşmış, milli tarihlerinden habersiz, iğreti tavırlı, kibirli ve hoppa adamlar halini” almasıdır (Alver, 2006: 167). Bu noktada bobstil tip, giyinişi, konuşması, davranışları, kendi kültürüne ve tarihine yabancılaşması noktasında gelenekteki züppe tipiyle özdeşleşir.

Züppe tipi ve bu tipin giyim kuşam ile Batılı görünme simgesi hâline gelen moda düşkünlükleri, Osmanlı'dan Cumhuriyet'e uzanan çizgide farklı görünüm ve isimlendirmelerle seyrine devam etmiştir. Bu isimlendirmelere göz atılacak olduğunda ilk olarak, kökü K1rım Muharebesi'ne dayanan Fransız kesimi sakalla özdeşleşmiş didon tipiyle karşılaşılır: "Didon, önceleri bütün Fransızlar için bir lakap gibi kullanılırken, daha sonra, onları taklit eden Türklere yapıştırılmış, 'alafranga' makamında olumsuz bir sıfat hâlini’” almıştır (Özgül, 2018:123). Reşat Ekrem Koçu'nun ifadesiyle didonlar, "giyim kuşamlarını, tuvaletlerini yabancı âlemin modalarına uydurmuş olanlardır” (1967: 90).

Didondan sonra "dostum, azizim” manasına gelen monşer, II. Abdülhamid devrinde alafranga tipler için yakıştırılan bir sözcüktür. Bu yakıştırma, Fransa'ya tahsile gidip tekrar yurda dönen gençlerin birbirlerine "lüzumlu, lüzumsuz, ifratla" monşer diye hitap etmelerinden, monşersiz cümle kullanmamalarından doğmuştur. Monşerler, "Paris modasına göre saç, 
sakal, bıyı kestirirler, daracık pantolon, yakaları gayet kapalı yelek ve ceket giyerler, feslerini başlarına şapkavari oturtup nakil vasıtalarında da çıkarırlar, ellerinde tutarlar, dizlerine koyarlar" (Karay, 12 Haziran 1941: 2).

Latin Amerika'dan dünyaya yayılmış bir dansın adı olan Tango, I. Dünya Savaşı öncesinde zamanın en son modasına uygun kıyafet manasını ihtiva ettiği gibi "züppece giyinmiş kadın” için kullanılmıştır. I. Dünya Savaşı sonlarında yine bir dans çeşidi olarak ortaya çıkan ve Türkiye'de 1925-1927 arasında yaygınlaşan Çarliston modasında da aynı durum söz konusudur. Bu tabir "fiyakalı ve züppe kimse" manasına geldiği gibi "aklı zıvanadan büsbütün çıkmış değilse de bir tahtası eksik, muvazenesiz, hoppa, güvenilmez” şahıslara yönelik kullanılmıştır (Karay, 12 Haziran 1941: 2). Ömrü kısa süren çarlistondan sonra türeyen yeni bir tip ise bobstildir.

Refik Halit Karay’a göre toplum, “yenilik düşkünleri tarafından benimsenip kapışılan, lüzumsuzca ve ölçüsüzce rağbet kazanan” her türlü meseleye sinirlenir; tepkisini alay ve hiciv şekline sokar (Karay, 12 Haziran 1941:3). Bu yenilikleri ifade eden kelimelerin delalet ettikleri manaları ise genişletip komikleştirir. Tango ve çarliston örneklerinde olduğu gibi bobstil kelimesi de bu tespite uyar niteliktedir. Nitekim bir moda tarzının tarifi olduğu gibi zaman içinde "garabet, tuhaflık, gülünçlük" sembolüne dönüşmüş (Femik, 18 Aralık 1940: 3); "havailiğe, züppeliğe, manasızlığa, garip, maceraî heveslerin peşinden koşmaya" (Münir, 15 İkincikanun 1941: 3) isim olmuştur. Ayrıca, en lüks mekânlardan sokak aralarındaki pazarlara kadar insanların haricinde her türlü yenilik, farklılık ve yabancılık için kullanılmıştır.

Bobstilin anlam genişlemesindeki son nokta, "esaslı küfürlerin" arasına dâhil olmasıdır. 1941'de Ulus gazetesinde çıkan bir haber iddiayı doğrulayacak içeriktedir. Münakaşa eden iki gençten biri, "dağarcıkta mevcut üstü açık ve kapalı bütün küfürleri kullanıp hazineyi tükettikten sonra" hıncını alamayarak "Seni gidi bobstil seni!” diyerek son kozunu oynar. Duyduğu tüm hakaretlere ses çıkarmayan genç, bobstil kelimesine tahammül edemez, "sensin bobstil!" diyerek tartışmayı alevlendirir. Davalık olan gençler, mahkeme koridorlarında "bir daha böyle ağır küfürler savurmamak şartıyla" barışırlar. Benzer hadise, bir fabrikada çalışan işçilerin birbirlerine bobstil demeleri üzerine ortaya çıkmış, mahkeme koridorlarına taşınmıştır (Kezege, 8 Şubat 1941: 2).

\section{Bobstil tipler}

Bobstil moda, 1940’lı yıllarda dış görünüşleri, davranışları, zevk ve tercihleri, iç dünyaları ile yeni bir tipe vücut vermiştir. Bir kıyafet modası olması itibariyle bu tipi belirgin kılan husus dış görünüştedir. Tarif edilecek olursa bobstil erkeklerin saçları ense köklerine kadar uzun, briyantin sürülü ve taralıdır (Nureddin, 6 Temmuz 1940: 3). Genellikle killi sakal bırakmayı tercih ederler (Sağnak, 14 Haziran 1941: 1). Uzun yakaya ve kollara sahip olan gömlekleri hem renkli hem de desenlidir. Ceketleri bol, boydan dizlere kadar uzun, düşük omuzludur. "Nohut iriliğinde bağlı, çiğ renkli", uzun kravat takarlar (Narlıkaya, 21 Ağustos 1941: 4). Pantolonları ceketleri gibi bol, fakat dar paçalı ve kısadır. Kemer yerine genellikle askı kullanırlar. Zira önemli bir meseleden bahsedecekleri zaman başparmaklarını bu askıya 
takma gereği hissederler (Acar, 16 Birincikanun 1940: 3). Pantolonun altına renkli ve desenli çorap giyerler (Coşkun, 15 Birinciteşrin 1940: 7). Ayaklarında ise kalın köseleden yahut üç parmak kalınlığında kauçukla kaplı, olması gerekenden büyük ayakkabıları vardır (Sağnak, 14 Haziran 1941: 1).

Bobstillerin yürüyüşleri mizah dergilerine malzeme teşkil edecek tuhaflıktadır. Onlar göğüslerini içeri çökerterek, sırtlarını kamburlaştırarak, kollarını ileri doğru sallayarak ve mutlaka elleri pantolon ceplerinde yürürler (A.N.K., 20 Birincikanun 1940: 6). Dış görünüşlerine dair olmazsa olmazlarından biri, sürekli ağızlarında taşıdıkları pipolarıdır. "Ağzının solunda dişlerine sıkıştırılmış kendi boyunda bir pipo" ile yürümek bobstillerin alışılagelmiş görüntüleridir (Gençosman, 14 Aralık 1940: 2).

Bobstil modayı takip eden erkekler olduğu gibi kadınların da varlığından söz etmek gerekir. Onlar, şapka olarak başlarına "hokkabazların külahını andıran sipsivri bir nesne geçirirler” (İntepe, 2 Aralık 1942: 2). Genellikle etekleri ile çorapları birbirini tamamlayacak uzunluktadır. Yazın çorapsız gezdikleri hâlde kışın kaba dikişli çoraplar giyerler. Ayakkabıları ise çeşitlilik gösterir; kimisininki "Babilin asma bahçeleri gibi” yüksek, kimisininki de “ninelerin hamur teknesi gibi” alçak, düz ve kabadır (İleri, 31 Birincikanun 1940: 4). Nejat Akdemir, Bobstil Kaynanaya Maşallah Ho Ho Ho adıyla yayımladığı kitapçıkta, bobstil bir kadının dış görünüşünü şöyle tarif etmiştir:

(...) modaya uymuş sıska bir haspa, leylek bacağı gibi ayaklarına bir karış eninde mantarlı ayakkabıları geçirmiş. Çorap yok, saç baş darmadağın, ayağına bakarsanız teninin rengini asla anlayamazsınız. Çünkü nerede dolaşmışsa oranın tozu tenine yapışmıştır. Bereket onun ayağı kokmaz. Çünkü parmakları iskarpinin kafeslerinden dışarı firlamıştır! Yalnız yürüdükçe topuğu kunduranın ökçesine iner, kalkar ve ağız şapırtısı gibi bir ses çıkarır (1943: 6).

Bobstil kadının el tırnakları mercan rengine, dudakları ise "hudutları çok taşkın olarak" kırmızıya boyalıdır. Kulaklarında taşları sahte elmastan gösterişli büyük küpeler vardır. Parmakları iri yüzüklerle, kolları kalın bileziklerle donanmıştır. Uzun kayışlara sahip çantaları omuzlarına takılıdır (Koçu, 1967: 41). Onlar, bobstil erkekler gibi devrin modasını takip etmeyi amaç edinmişlerdir. Kıyafetlerinin dışında konuşmaları, davranışları ve iç dünyaları ile bobstil erkeklerden farksızdırlar.

Bobstiller birbirlerine genellikle "ekselans" diye hitap ederler. Ağızlarında "bozuk, yanlış, kötü bir İngilizce ile karışık caz mırıltıları” vardır (A.N.K., 20 Birincikanun 1940: 6). Amerika'dan dünyaya yayılmış bir caz akımı olan Swing müziğe hayranlıkları, tesiri altında kaldıkları kültürün getirisi olarak görülmelidir.

Hayatın merkezine eğlenceyi koyan bobstiller, tüketim odaklı yaşarlar. Çalışmayıp üretmedikleri için daima ailelerine muhtaçtırlar. Onlardan aldıkları harçlık ile günlerini geçirirler, sonraki günün hesabını yapmazlar. Harçlık alamadıkları günlerde de paraları varmış gibi her yere girip çıkmayı alışkanlık hâline getirmişlerdir (Sağnak, 14 Haziran 1941: 1). Bahsedilen özelliğiyle bobstil, modern hayatın aylak tipleriyle benzerlik taşır. 
Bobstiller, içinde yaşadıkları topluma yabancılaşmış, millî ve manevi değerlere kayıtsız tiplerdir. Nusret Safa Coşkun, 1940 yılında bobstil bir gençle yaptığı röportajda, onların kendi kültürlerine yabancılıklarını selâmlaşma üzerinden örneklendirmiştir: Bobstil genç, Hollywood'daki artistlerin "sol el ile ters" el sıkıştıklarını bildiği hâlde bunun Anadolu'daki formuna yabancıdır (Coşkun, 15 Birinciteşrin 1940: 7). Zira onlar içinde yaşadıkları toplumun yozlaşmış ve aykırı tipleridir. Bahsi geçen aykırılık ahlak ve terbiye noksanlığına kadar uzanır. Bobstil iki gencin konuşmalarına kulak misafiri olan Şefket Rado, "baba” kelimesinden hareketle bu noksanlığ bahsederken, diğeri de sözlerine "bizim ihtiyar” diye başlar. Şevket Rado, eskiden gençlerin babalarına karşı yazı ile yahut şifahen hitap etmelerinin büyük dikkat gerektirdiğini belirterek bobstil gençleri eleştirmiştir (Rado, 8 Eylül 1943: 2).

\section{Bobstil edebiyat yahut bobstil modanın edebî metinlere yansıması}

Bobstil modanın edebiyatla ilişkisini üç başlık altında değerlendirmek mümkündür. Bunlardan ilki, 1940'lı yıllarda giyim tarzlarıyla ve "garip" karşılanan şiirleriyle gündemde olup kendileri "bobstil şair", eserleri de "bobstil şiir" yakıştırmasına uğrayan şairlerle ilgilidir. İkinci ve üçüncü başlıklar, bobstil modanın edebî metinlerde ortaya çıkardığı tiplerle ilgilidir. Bu tiplerden biri, bobstil modayı takip etmekle birlikte edebiyat ve sanatla ilgilenen, mecmua çıkarma hevesi içinde olan; geçmişteki şairleri, hâlihazırdaki şiir dilini ve formunu reddedip yeninin peşinde koşan ancak yazdıkları "anlamsız" karşılanan bobstil şair tipidir. Diğeri ise milli ve manevi değerlere yabancılığı, giyim kuşamı, özenti tavırları ile yeni bir züppe tipi olarak karşılanan sosyal hayattaki bobstil gençlerdir.

\subsection{0'lı yıllarda garip şair, bobstil şiir}

Bobstil moda ve edebiyat ilişkisinden bahsedilecek olduğunda dönemin Türk şiirine, bilhassa Orhan Veli, Oktay Rifat ve Melih Cevdet'in oluşturduğu Garip Hareketi'ne göz atmak gerekir. Zira bobstillere yönelik kaleme alınan yazılarda Orhan Veli ve arkadaşlarına sıklıkla gönderme yapıldığı görülmüştür. 1940’ta Ensondakika imzasıyla yayımlanan “Bobstil Tip, Bobstil Şiir" başlıklı yazı bunun en dikkat çekici örneklerindendir:

$\mathrm{Bu}$ tipleri İstanbul'a ister bir Ermeni terzisi, isterse bir Amerikan kaçkını hediye etsin; fakat bu tiplerle yeni şairlerin eserleri arasında mükemmel bir münasebet olduğunu da unutmayınız. 'Yazık oldu Süleyman Efendiye' şairinin mısraıyla kadınları sağmal ineklere teşbih eden bir Çelebiye ait fikirlerin, Beyoğlu'nda mukim bir gence giydirilmiş Bobstil yahut Halifaks stil bir ceketten ne farkı var ki? Acaiplik birisinin dışındaysa birisinin de içindedir! Neyse ki bobstil kıyafetle Bobstil şiiri birleştiren bir muhteva henüz zuhur etmediği için halimize şükredip oturalım (25 Birinciteşrin 1940: 2).

Orhan Veli’nin “Kitabe-i Seng-i Mezar” şiirine gönderme yapılan yazıda, dönemin bobstil gençleriyle Garipçilerin “yeni şiir”leri arasında münasebet kurulur; şiirde yenilik olarak sunulan şekil ve muhteva unsurları ile bobstil gençlerin kıyafetleri arasında fark görülmez. 
Yücel dergisinde "Edebî Hatıralar, Fıkralar" başlığg altında kaleme alınan bir anekdotta da aynı bahse dikkat çekilir. Ayakkabılarının bir tekini kırmızı diğerini siyah giyen şairin "şiirdeki yeni zevki ve kayıtsızlığı giyimde de tatbik etmek" istediği belirtilir ([İsimsiz], Sonkanun 1941: 86). Anekdotun yer aldığı tarih göz önünde tutulacak olduğunda, Garip şairlerinin kastedildiğini anlamak mümkündür. Bu noktada sorgulanması gereken husus, Garipçilerin Türk şiirinde neyi değişstirdikleri yahut Türk şiirine yeni olarak neyi getirdikleridir.

Orhan Veli ve arkadaşları Garip tarzı ilk şiirlerini Varlık dergisinde 15 Eylül 1937 tarihli sayısında yayımlamışlardır. 1941'te ise şiir hakkındaki görüşlerini bir bildirge hâline dönüştürüp kamuoyuyla paylaşmış ve Garip şiirlerini bir kitapta toplamışlardır. Bu hareketin temelinde "nesnel gerçekliğe ve doğallığa dayalı bir estetik alt yapı" mevcuttur. Bu yalınlık düşüncesi, onların "vezin, kafiye, ahenk gibi teknik öğelerle sözcüğün mecazî anlamını ön plana çıkaran edebî sanatları ve daha geniş anlamda imgeyi” şiirden atmalarına neden olmuştur. Diğer taraftan toplumun orta ve alt tabakalarını dikkate aldıkları için söz varlıklarında “deyim, argo, kalıp söz gibi öğeler” ile halkın konuştuğu günlük dili esas almışlardır (Sazyek, 1996: 349-350). Alışılagelen yerleşik şiir tarzına karşı olan Garip şiiri, basın ve edebiyat çevrilerinde tepkiyle karşılanmıştır. Orhan Veli'nin 1938'de İnsan dergisinde yayımlanan "Ali Rıza ile Ahmet'in Hikâyesi”, "Mangal” ve "Baş Ağrısı" şiirleri alaya alınmıştır (Sazyek, 1996: 52). Bu şiirler arasında bilhassa "Kitabe-i Seng-i Mezar”, birkaç yıl içerisinde türlü nedenlerle edebiyat gündemini meşgul etmiş, hafızalarda yerini koruyan "Yazık oldu Süleyman Efendiye!..” mısraı ise 1940'lı yılların sonuna kadar tartışma konusu olmuştur.

Gelenekteki şiirden farklı, şekil ve muhteva itibariyle yeni şiirlerle ortaya çıkan Garipçiler, dönemin züppe gençlerine yönelik kullanılan "bobstil” yakıştırmasında olduğu gibi, "bobstil şairler” olarak nitelendirilmişlerdir. Vâlâ Nureddin, “'Bobstil' ve 'Süleyman Efendi"” başlıklı yazısında Garip şiirini, Orhan Veli’nin "Yazık Oldu Süleyman Efendiye" mısraından hareketle bobstil şiir olarak değerlendirmiştir (Nureddin, 3 Nisan 1941: 3). Orhan Seyfi Orhon; karikatür, fikra ve komik şiirlerle bobstillere geniş yer ayıran Akbaba mecmuasında kaleme aldığ 1 "Edebiyat Sohbeti” başlıklı yazısında, Garipçilerden "bobstil şair" olarak bahsetmiştir. Attilâ İlhan, Mavi dergisinde yayımlanan "Sosyal Realizmin Münasebetleri Yahut Başlangıç” yazısında 1940'lı yıllardaki şiiri üç ana başlıkta değerlendirmiştir. Bunlardan ilki, işin alayında görünen, şiirle espriyi karıştıran; "tuhaflıkları, sürrealist oyunları 'yeni sanat' diye ortaya" süren "Bobstiller"dir (İlhan, 1 Temmuz 1954: 1); diğer ifadeyle Orhan Veli ve arkadaşlarının oluşturduğu Garipçilerdir.

Asaf Halet Çelebi, bobstil moda ve bobstil şiir mevzubahis olunca akla gelen bir diğer isimdir. Masal türünden, tasavvuf ve uzakdoğu mistiszminden beslenen Asaf Halet, 1938'den sonra yazdığı şiirler ile yadırganır, garip karşılanır; "anlamsız ve anlaşılmaz” bir şair olarak görülür. Aynı zamanda, "şiir okuyuşu, toptoparlak vücudu, aşağı sarkan upuzun bıyıkları, yakasından hiç eksik etmediği çiçeği, dar ve paçaları kısa pantolonlarıyla zamanın mizah dergilerinin vazgeçilmez malzemesi” olur (Gülendam, 2009: 1192). Hem şiirleri hem de giyim tarzı Asaf Halet'in "mistik şair"in ötesinde, "bobstil şair" yakıştırmasıyla anılmasına sebeptir. Hikmet Feridun Es, "Bobstil Edebiyat” başlıklı yazısında, bu görüşü destekleyecek içerikte bir yazı kaleme almıştır. Bobstil kıyafet modası gibi bobstil edebiyatın, şiirin, 
mısraların ve beyitlerin de varlığından söz eden yazar, Asaf Halet'in "Sidharta" şiirindeki "om mani padme hum" mısralarını örnek göstermiştir. Güya mısraların sonundaki "(3 kere)" ibarelerinin bir izahat değil, şiirin ana unsuruna dâhil olduğunu belirterek bobstil edebiyata örnek bir metin göstermiştir (Es, 17 Ağustos 1940: 3).

Giyim tarzları ve şiirleriyle bobstil yakıştırmasına uğrayan şairler, sadece eleştiri yazılarıyla değil, mizahî şiirlerle de hedef olmuşlardır. Tahir Olgun’un "Bob-stil Şair'e” başlığıyla kaleme aldığı; "A çocuk kalmışsın ilimde sıska/ Ne ilaç kâr eder sana ne muska" dizeleri, bobstil şairlerin cahil olduğu iddiasını taşır (Yücebaş, 1976: 338). Cahit Saffet [Irgat]'ın Çınaraltı dergisinde "Bobstil Şiirler" başlığı altında "Yolculuk" adlı şiiri yayımlanır. Anlamsızlığıyla ön plana çıkan bu şiir, bobstil şairlere ve onların şiirlerine bir eleştiri mahiyetinde yazılmıştır.

Yalnız ve çıplak çıktı evimden

-Hoşça kalın demedi

Ne bohça aldı

Ne bir selâm götürdü

Cennetin kapısını açtırmak için

Ne imamdan kartvizit,

Karım böyle göç etti öbür dünyaya;

Şerefine içiyorum o gündenberi

Ne halt eder tek başına dolap beygiri? (19 Birincikanun 1942: 112).

Verilen örneklerde şairlere ve şiirlere yönelik eleştirel bir mana taşıyan bobstil kavramı, aynı zamanda devrin sosyete kadınlarını ve züppe gençlerini karşılamak üzere şiir diline dâhil olmuştur. Orhan Veli, bobstil eleştirisine maruz kalmasına rağmen, "Altın Dişlim” adlı şiirinde hem zihinleri hem dış görünüşleriyle bobstil modaya uygun kadınları konu edinmiştir:

Gel benim canımın içi, gel yanıma

İpek çoraplar alayım sana

Taksilere bindireyim

Çalgilara götüreyim seni

Gel,

Gel benim altın dişlim

Sürmelim, ondüle saçlım, yosmam;

Mantar topuklum, bobsitilim, gel (Kanık, 1982: 156).

Türk edebiyatında hicivleriyle tanınan Neyzen Tevfik de bobstil modaya karşı kayıtsız kalmayarak bir dörtlük kaleme almıştır:

Bir taraftan câm-1 aşkın, bir taraftan meyle ney

Kör-kütük, zil-zurnayım; sâki fitil ettin beni

Serhoşum, kör kandilim, yandım o mavi gözlere

Altmışından sonra cânâ bobstil ettin beni! (2009: 132). 
Bobstil modayı eleştiren Neyzen Tevfik, aynı zamanda devrin moda düşkünü kadınlarının bobstil erkeklere meyline dikkat çekmiştir. Hikâyelerdeki bobstil kahramanlarda görüleceği üzere bir erkeğin bobstil tarzda giyinmesi, kadınların ilgisini çekmek için yeterli ölçüttür.

\subsection{Edebi metinlerdeki bobstil şair tipi}

Edebî metinlerde bobstillerin izi sürülürken en çok dikkat çeken tip bobstil şairlerdir. Sosyal hayatın bu tiplerine yönelik bir roman, tiyatro metni, şiir ve iki kısa hikâye tespit edilmiştir. Bahsi geçen metinlerin hepsi de 1940'ların ilk yıllarında yayımlanmıştır. Dolayısıyla bu metinlerin, mizahın ötesinde, dönemin Türk şairlerine ve yeni şiirlere bir eleştiri amacıyla yazıldığı söylenebilir.

Bobstil şair tipi iki alt başlıkta ele alınmıştır. Bu başlıklardan biri, Ercüment Ekrem Talu'nun kitaplaşmamış kırk üç tefrikalık "Bobstil Şair” romanına ayrılmıştır. Bahsi geçen romanın konuyla birebir örtüşmesi, bobstil şair tipini geniş bir perspektiften ele alması ve hacmi bu başlığı gerekli kılan unsurlardır. Piyes, şiir ve kısa hikâyelerde yer alan bobstil şair tipleri ise önemleri ve hacimleri göz önünde bulundurularak ikinci alt başl1kta incelenmiştir.

\subsubsection{Ercüment Ekrem Talu'nun “Bobstil şair”i}

Ercüment Ekrem' in "Bobstil Şair” romanında, Osmanlı'dan Cumhuriyet'e uzanan dört nesil yer alır. Adı önce Orhan olarak anılan daha sonra Turhan'a çevrilen bobstil şair tipi ise bu neslin son mensubudur. ${ }^{1}$ Ercüment Ekrem, Turhan'ın aile efradı, eğitimi, arkadaş çevresi hakkında bilgi verip edebiyat ve sanat hakkındaki düşüncelerine, kaleme aldığı şiirlere yer vererek bobstil şair tipinin portresini çizer. Karşısına çıkardığı millî bilince sahip, şuurlu tiplerle de vatan ve millet sevgisine hâiz ideal gençliğin nasıl olması gerektiğini ortaya koyar.

Turhan, bir Osmanlı ailesinin çocuğu olarak dünyaya gelse de anne ve baba soyundan Türk ırkına mensup değildir. Annesi Safiye Hanım Rus ve İtalyan, babası İskender Bey ise Slav kanı taşır. Turhan'ın soyundan gelen yabancılık, yeterince beslenemediği için Yunan adalarından tutulan Androslu sütnine ile bir kat daha artar (Talu, 22 Eylül 1942: 2). Kısaca özetlenen aile unsuru ile Ercüment Ekrem, Turhan'ın Türk milletinin milli ve manevi değerlerine karşı yabancılığgna ırkî bir dayanak gösterir.

Turhan'ın aile çevresine, yetiştiği muhite bağlı olarak "Rum, Ermeni Yahudi ve Levanten çocukları[ndan]” oluşan arkadaş çevresi eklenir (Talu, 22 Eylül 1942: 2). Okul çağı geldiğinde Parmakkapı'daki papaz mektebine yazdırılır. Turhan, burada Fransızca fennî ilimleri, bir Ermeni hocadan da Türkçeyi öğrenir. Edebiyata biraz hevesi olduğu hâlde okumak için seçtiği sanatkârlar onun ruhu ve ahlakı üzerinde iyi tesir bırakmazlar. Başucu kitapları Maupassant'ın hikâyeleri, Verlaine'in, Baudelaire'in, Rimbaud'nun şiirleridir. Bunları tam manasıyla anlayamadığı hâlde okur; "çünkü bunların içindeki tasvirleri, fikirleri kendi hasta, daha doğrusu bozuk, müşevveş ruh[una]" uygun bulur. Türkçe eserleri ise asla sevmez. Dillerini anlayamasa da Namık Kemal'i "gülünç, maskara"; Abdülhak Hamid'i "kötü aktör" olarak görür. Konuşurken her cümlesine mutlaka yabancı kelimeler ekler, Türkçe kelimelerin çoğunu yanlış telaffuz eder (Talu, 26 Eylül 1942: 2). 
Kendisini büyük bir şair, "nasipsiz bir dahi” olarak gören Turhan, hakkı olan şöhrete erişmek sevdasıyla yanıp tutuşur. Bu hedefinin gerçekleşmesine engel gördüğü "müesses şöhret sahiplerini de benliğini kemiren sonsuz bir hasetle" kıskanır (Talu, 27 Eylül 1942: 2). Eski divanları okur, onlarda yer alan şiirleri taklide yeltenir. Aruz veznini bilmediğinden ve kelime haznesinin darlığından dolayı taklidi bile beceremez. Ancak kabahati divan şairlerinde bulur.

Garp edebiyatının sone tarzına yönelen Turhan, yazdığı şiirler için mecmua arayışına girse de hiçbir yayıncıdan karşılık bulamaz. Bu başarısızlık onun ahlakına tesir eder; "dünya nizamına karşı bayağı düşman" hâline getirir. O, "bir taraftan her istediklerini yapabilen burjuva sınıfına kin güder, diğer taraftan sivrilmiş salahiyetlerden de nefret eder" (Talu, 28 Eylül 1942: 2). Bir mecmua çıkarıp edebiyatta inkılâp vücuda getirmeyi kafasına koyar. İlk birkaç sayıdan sonra elli bin, yüz bin basmayı hedefler. Güya bütün Türkiye ve hatta Türk dilini konuşup anlayan tüm ülkeler mecmuasını kapışacaktır. Çıkaracağı mecmuya "Morg” ismini bulmuştur. Baudelaire'i akla getiren bu isim ile Turhan, "Fransız şairine minnet borcunu birazcık da ödemiş” olacak, aynı zamanda öldüreceği şöhretleri teşhir edecektir” (Talu, 28 Eylül 1942: 2).

Turhan'ın, bobstil gençlerin genel özelliklerine uygun olarak, kendi kazanciyla elde ettiği bir geliri yoktur. Ailesi de Morg mecmuasını çıkartmak için sermaye temini noktasında ona yardımcı olmaz. Turhan, "Şeri” diye seslendiği Şakir adlı arkadaşının maddi desteği ile hayal ettiği mecmuayı çıkarmaya muvaffak olur. Şeri’nin kılık ve kıyafeti arkadaşlarınınkine benzemez; o temiz ve düzgün giyinir. Bol para harcar, cebi arkadaşlarına her daim açıktır. Ercüment Ekrem'in deyimiyle onun bobstilliği sadece ruhundadır: "Dişından görene rabıtalı bir insan hissini verir" (Talu, 29 Eylül 1942: 2). Turhan gibi arkadaşı Şeri de şiire meraklıdır. Fakat şiirlerini önce Fransızca olarak yazar, daha sonra "güya" Türkçeye çevirir. Arkadaşları, ortaya çıkan “alelacayip şeyleri” pek orijinal bulur. Turhan'ın teşviki, Şeri'nin de para desteğiyle yayın hayatına atılan Morg mecmuası piyasada beklenen ilgiyi görmez. İkinci ve üçüncü sayıları ilki kadar da satılmaz. Matbaacı, elinde başka işler olduğunu bahane ederek Turhan'la arkadaşını nazikâne uzaklaştırır. Mecmuada yayımlanan şiirlerden ikisi şöyledir:

İBRIKK

Boynun bükülü durur, en mundar

Yerlerde...

İçindeki su...

En hakir işleri görür.

Kırık kulpun, andırır

Benim

Yar elinde mıncıklanan gönlümü (Talu, 29 Eylül 1942: 2).

\section{FOTINIMIN TABANI}

Basıp basıp, kaldırıma, asfalta

Fotinimin tabanları aşındı..

Deliklerinden içeriye toz girmiş..

Ayaklarım tatlı tatlı kaşındı (Talu, 29 Eylül 1942: 2). 
Metnin başından itibaren ortaya çıkan portre, aslında bobstil şair tipini ortaya çıkarmıştır. Genel bir değerlendirme yapılacak olduğunda Turhan'da vücut bulan şair tipi, Türk edebiyatının büyük şair ve yazarlarına düşmandır. Türk kültürüne yabancı, milli ve manevi değerlere kayıtsızdır. Üretmez, çalışmadan yaşam sürer. Devriyle uyuşmayan fikirlerini yaymak ve yeni tarzdaki şiirlerini yayımlamak için mecmua çıkarma isteğindedir. Morg mecmuasında yayımlanan şiirleri, ilk dikkatte anlamsızlığı ve basitliğiyle dikkati çeker. Mecazî anlamdan ve sanatlı bir söylemden uzak olan şiirlerde mısra bütünlüğü, vezin ve kafiye de dikkate alınmamıştır.

Ercüment Ekrem, bobstil tipin milli ve manevi değerlere, geçmişin büyük şairlerine ve alışılagelen şiir anlayışına kayıtsızlığ 1 karşısında kurguya sık sık müdahele ederek eleştirel tutumunu yineler. Bobstil tipi daha iyi canlandırabilmek, ideal olanı gösterebilmek maksadıyla Turhan'ın karşısına milli kimliğini muhafaza eden Yedek Subay Yavuz, Teğmen Ali Bahtiyar ve Anadolu gençlerini çıkarır. Olay örgüsüne bağlı olarak romanın ilerleyen kısımları bu karşılaşmalarla örülüdür. Ercüment Ekrem, inkılâp neslinin ideal tipleri üzerinden adeta Turhan'a cevap vererek, kendi düşüncelerini açıklamıştır. Zira Türkiye Cumhuriyet ile kıyafetleri, vücut yapıları, bilgi seviyeleri, millî ve manevî değerlere bağlılıkları yönünden örnek bir nesil/inkılâp nesli ortaya çıkarma isteği mevcuttur. Bu nesil, yeni kurulan Türkiye'yi aydınlık yarınlara taşıyacak olan ülkenin genç evlatlarıdır. 1940'lı yıllarda Bobstil modayı takip eden gençlik ise kıyafetlerindeki zevksizlik, duruş bozuklukları başta olmak üzere yabancı sözcüklerle konuşmaları, milli ve manevi değerlerden uzak yaşamları, Türk kültürüne yabancılıkları, taklitçi bir yapı arz etmeleri bakımından beklenen/hedeflenen ile taban tabana zıtlık göstermektedir. Dolayısıyla bobstiller, inkılâbı koruyan aydınların/otoritenin kabul edebileceği standartların dışında kalmışlardır. Bunun tipik bir örneği olan Turhan da roman boyunca Ercüment Ekrem'in hedefi olmuştur.

Roman dişında bobstillere yönelik en sert tepkiyi gösterenlerden biri, "Bobstil ve Maarif” başlıklı yazısıyla yine Ercüment Ekrem Talu'dur. Ona göre meziyetleriyle sivrilemeyen gençler, bobstil modaya uyarak akranları arasında dikkat çekmeye çalışırlar. Yazarın ifadesiyle Türk aileleri, bu modaya uyan evlatları karşısında, "üzerine yattığı yumurtalardan civciv yerine kaz palazı çıktığını hayretle gören kuluçka tavuğa" dönerler (Talu, 20 Birincikanun 1940: 2). Ancak bu moda akımı, ailelerin ötesinde Cumhuriyet Türkiye'sine, yeni ideal gençliğe zarar vermektedir. Ercüment Ekrem, bobstilleri eleştirirken Cumhuriyet gençliğinin vasıflarını sıraladığ 1 gibi Maarif Vekâleti’nin kılık ve kıyafet düzenlemesine ihtiyaç duyduğunu belirtir.

\subsubsection{Edebi metinlerdeki bobstil şair tipi}

Ercüment Ekrem'in "Bobstil Şair” romanının dışında, bahsi geçen tipi konu edinen daha çok mizah ve hiciv kaygısıyla yazılmış çeşitli türde metinler mevcuttur. Bunlardan birisi, F. Gariboğlu imzasıyla Akbaba mecmuasında yayımlanır. "Bir Perdelik Facia" alt başlığını taşıyan "Bobstil" adlı tiyatro metninde, dış görünüşleriyle tam manasıyla bobstil özelliği gösteren beş arkadaş vardır. Bobstil gençler bir kahvede oturup muhabbet ederken zar atarak reislerini seçerler ve çıkaracakları "fikir-sanat” mecmuasına isim bulmaya çalışırlar. Gençlerden ilki eski 
şairlere karşı açacakları mücadeleyi tanımlayacak içerikte "bombardıman"1; diğerleri ise "dinamit" ve "barut" isimlerini öne sürerler. C şahsı tarafından "pek bayağı" bulunan bu isimlerin yerine "Edişin Of Ücükeyşin" teklif edilir ve oy birliğiyle kabul edilir. İsimden sonra sıra görev taksimine gelir. Zira hepsi bir idari işle ilgilenecek, aynı zamanda mecmuanın yazarı olacaklardır. Bu meseleyi de çözüme kavuşturan bobstil gençler dergi için malî meseleye çözüm ararlar ancak hiçbirinin parası yoktur. Piyango bileti satın alarak ikramiyenin çıkması durumunda derhal işe başlamaya karar verirler. Lakin iki lira tutan piyango bileti için gerekli parayı beşe bölemezler ve mecmua işinden vazgeçerler (İkinciteşrin 1940: 5-6).

Yusuf Ziya Ortaç, Akbaba mecmuasında “İstemezük” adıyla yayımladığı ve "Ankara' da toplanan Maarif Şurasına İthaf” ettiği şiirinde bobstil bir şairin tarifini yapar. Bu bobstil gencin kaşları teyel, bıyıkları incedir. Eski bir softanın cüppesine benzeyen ceket giymiştir; kalender meşreptir. Henüz yirmi yaşında olmasına rağmen kambur yürür. Gömleğinin yakası ise yağ içindedir. Paçaları yerden bir karış uzaktadır. Gözlerinde esrarlı bir yakarış vardır. Boyunbağı yeşillidir, allıdır; iskarpini çifter çifter nallıdır. Bahsi geçen ifadelerle genel manada bobstil tarifi yapan Yusuf Ziya, daha sonra bu gencin edebiyatla münasebetine değinir. "Bir kahpeyi” övüp Mehmet EminYurdakul'a söverek şiir yazan genç, "kof ve fostur.” Vezinden anlamaz, kafiyeye de ilgisi yoktur. Kelimeden rakamı ayıramayacak kadar cahil olan gencin bilgisi de bilmemektedir. Yusuf Ziya, çizdiği şair portresi karşısında tavrını ortaya koyarak, "Türk milleti kabul etmez böyle piç!” misraına yer verir. Daha sonra, "Haydi Yücel! Vur yumruğu durma, ez!” diyerek dönemin Maarif Vekili Hasan Âli Yücel’i bobstillere karş1 göreve davet eder (Çimdik, 25 Şubat 1943: 5).

Yusuf Ziya'nın 1943'teki çağrısı, 1940 yılında gazetelere yansıyan bir düzenlemeyi akla getirir. Hasan Âli Yücel'in başında bulunduğu Maarif Vekâleti, 1940 yılında bobstillerin eğitim kurumlarından menedilmeleri için kılık ve kıyafet düzenlemesi getirmiştir. 17 Kânunuevvel 1940 tarihli Cumhuriyet gazetesinde, "Talebeler Bobstil Elbise Giyemeyecek" başlığı taşıyan şu haber yer almaktadır. "Maarif Vekaleti talebelerin bobstil tarzında elbise giymelerini menettiğinden bundan sonra bütün mekteplerde bu yolda da teftişler başlayacaktır." ([İsimsiz], 17 Kânunuevvel 1940: 2). Bir gün sonra Akşam gazetesinde isimsiz yayımlanan bir yazıda ise "irfan semalarını kaplayan bir tehlikeye karşı böyle bir tedbir[in]" yerinde olduğu, ebeveynler ile maarifin yekvücut bir cephe teşkil etmesi gerektiği belirtilir (İsimsiz, 18 Kânunuevvel 1940: 1).

Reşat Feyzi'nin 1940’ta Son Telgraf'ta yayımlanan “Bobstil Şair” başlıklı bir hikâyesi vardır. Hikâyenin kahramanı olan genç, yazı işleri müdürü Senih Muammer’i görmek üzere gazete idaresine gider. Kapıcının genç şairi tarifi, tam manasıyla bobstil modanın özelliklerini taşıyacak içeriktedir: "Efendim, hem genç, hem ihtiyar, genç amma, daha bu yaşta kamburu çıkmış... Kolları sarkmış. Dudaklarının üstünde- huzurunuzdan uzak- sümük gibi bıyıkları var" (Feyzi, 19 Birincikanun 1940: 4). Senih Muammer'in odasına giren genç şair, kendisini tanıttıktan sonra şiire dair düşüncelerinden ve şairlik iddiasından bahseden cümleler sarf eder. Senih Muammer, genç şairin konuşmasını bitirmesinden sonra şiir defterini alır; ancak "ne imla, ne kelime, ne cümle, ne nokta, ne de virgül" bulunan metinleri okuyamaz. Bunun üzerine genç şair defterini geri ister ve aşağıdaki şiiri okur: 
"Ey budala Balalayka

Bozuk paran yoksa in

Tramvayın kapisından

Kunduranın içine gir

Kunduram bizim moruktan

Zorla sızdırılmış olan

Yirmi papele alındi.

Kunduram, ah bu kunduram

Bir pasta kutusu gibi

Kandırır enayi kızı" (Feyzi, 19 Birincikanun 1940: 4).

Reşat Feyzi'nin şair tipi dış görünüşü itibariyle bobstildir. Cahil olmasına rağmen iddialıdır. Gelenekteki şairleri, hâlihazırdaki şiir dilini reddeder. Şiire "yepyeni duyuşlar, görüşler, şekiller, mana ve mefhumlar” getirdiğini düşünür. Lisanı, grameri, lügati ve kaideleri “eski köhne telakkiler" olarak nitelendirip reddeder. Yukarıdaki alıntıda görüleceği üzere anlamsızlık şiirlerinin ayırıcı vasfıdır.

Bobstil şairlere dair bir diğer metin, 1944'de Yeni Sabah gazetesinde Çalçene ${ }^{2}$ müstearıyla yayımlanan “Karagöz Küllük Şairi”dir. Kendi aralarında sohbet eden Karagöz ile Hacivat, bobstil şairlerin vakit geçirdiği Küllük kahvesine giderek muhabbetlerine orada devam etmek isterler. Karagöz ile Hacivat'ı karşılarında gören bobstil şairler yarı Türkçe yarı Fransızca sözcüklerle şaşkınlıklarını gösterirler. Kök ve kimlik sorununa delalet eden bu konuşma biçimi, Tanzimat romanlarındaki züppe tipi gibi bobstillerin içinde yaşadıkları toplumdan kopuşunun bir simgesi olarak görülebilir. Samimi tavırlarla karşılamanın ardından bobstil şairler Karagöz ile Hacivat'a kendi yazdıkları şiirlerden okurlar:

"Cebine merdiven kurdum

Ben o çipil gözlü yârin.

Kolları boynuma doland1.

Şahland1...

Miydem buland1..

Cividi...

Suland1..

Kurduğum merdivenden

Aşağı...

Teker..

Meker..

Gönlüm yuvarlandı" (Çalçene, 25 Haziran 1944: 2).

Okunan birkaç şiirin ardından Karagöz de bobstil şairlere eşlik eder. Geleneksel Türk seyirlik sanatlarının önde gelenlerinden Karagöz ile Hacivat'ın bobstil şairlerle bir araya getirilmesi, mizahın ortaya çıkmasına imkân sağlar. Yazar, bobstil şairlerin manasız ve âhenksiz şiirlerini, Karagöz'ün bir anda aklına gelen sözcüklerle eşdeğer tutmuştur. Karagöz'ün dilinden 'Bunlar şair, öyle mi?” ifadeleriyle de bobstil şairleri ve onların yeni şiirlerini açıç̧a eleştirmiştir. 


\subsection{Hikâye kahramanı bobstil gençler}

Şair tipi dışındaki bobstillerin ele alındığı metinler hikâye türündedir. Tespit edilen metinlerin ikisi kitapçık olarak nitelendirilebilecek kısa metinlerdir. Bunların dışında, bobstillerin hikâye kahramanı olduğu günlük gazetelerde yayımlanmış yedi hikâyeye ulaşılmıştır. Hikâyelerin ortak özelliği bobstil gençlerin bir olay etrafında mizah çeşnisi de eklenerek alaya alınması, eleştirilmesidir.

Bobstillere dair dikkat çekici metinlerden biri, Hakkı Bigeç'in kaleme aldığı Bobstil Futbolcu'dur. Kadıköy vapuruna binen bir bobstil, karşısında oturan genç ve güzel bir kızın dikkatini çekmek, onunla arkadaş olmak ister. Bu sırada yanlarından geçen gençler, onu yabancı ülkede oynayan ünlü bir futbolcuya benzetirler. Hemen yanına giderek tanışırlar, üç senedir devam eden futbol turnuvalarına davet ederler. Bobstil genç, futbol oynamayı bilmediği hâlde, karşısındaki kızın ilgisini çekip arkadaş olmak uğruna turnuvaya gitmeyi kabul eder. Futbol sahasına gittiklerinde kendisi için forma hazırlanır. Ancak bobstil gencin futbol oynamak için şartları vardır. Bobstillerin özelliklerine uygun olarak, maç sırasında swing müzik çalınmasını ister. Diğer şartı ise sahaya ağzındaki pipoyla çıkmaktır. Bobstil genç, tesadüf eseri maçta bir gol atmayı başarır. Oyuna devam ettiği takdirde rezil olacağını bildiği için alkışlar eşliğinde oyundan çıkar. Oynadığı bu maçın kârı ise kızın ilgisini çekmesi ve kol kola stattan ayrilmasidir (1941: 3-14).

Bobstil Futbolcu hikâyesi, bobstil gençlerin başıboşluğuna, aylaklığına, düşünmeden yaşamalarına bir eleştiri niteliğindedir. Futbolcu olmadığı hâlde maç yapmayı kabul edişi, sahaya çıkmak için sunduğu teklifler bobstil tipin hayat karşısındaki absürt tutumunun bir göstergesidir. Aynı şekilde vapurdaki genç kızın, sırf futbolcu olmasından ve modaya uygun giyim tarzından dolayı bobstil gençle dostluk kurması ise bir başka eleştirel unsurdur.

Bobstillerin konu edildiği metinlerden bir diğeri, Selami Münir Yurdatap'ın Nasrettin Hoca Bobstiller Arasında adlı hikâyesidir. Nasrettin Hoca, bir yaz ayında Akşehir'den eşeğine binerek İstanbul'a gezmeye gider. Kaldığı otelin sahibinin tavsiyesi üzerine ilk olarak Moda'da kayık yarışlarını izleyecektir. Moda'ya gitmek üzere yola çıktığında, Akşehir'den babalarını tanıdığı Leyla ve Tayyar adlı bobstil gençlerle karşılaşır. Bu iki gence, kızlı erkekli bir gruptan oluşan bobstil arkadaşları da dâhil olur. Hikâye, Nasrettin Hoca'nın bobstil gençlerle olan muhabbeti ve maceraları üzerine kuruludur.

Nasrettin Hoca, ilk olarak Tayyar ile Leyla'yla karşılaştı̆̆ında onların kıyafetlerine dikkat eder. Leyla, "takunya gibi” kaba ayakkabılar ve kısa bir etek giymiştir. Tayyar ise saçlarını ensesine kadar uzatmış, üstünde babasının ceketi ve yirmi beş sene önce giydiği kravat, ayağında da küçük kardeşinin daracık pantolonu vardır. Gençlerin üzerindeki kıyafetlere anlam vermeye çalışan Nasrettin Hoca, bu kıyafetlerin moda olduğunu, adına da bobstil modası dendiğini öğrenir.

Tayyar ve Leyla'nın bobstil arkadaşları vapura geldiklerinde, birbirleriyle "Helo Lili... Helo Taylor!..” diye selamlaşırlar. Gençlerden biri, bu kısaltmaların manasını soran Nasrettin Hoca'ya resimler göstererek açıklama yapar: "Bak bu meşhur Robert Taylor, bu da Lili Damita. Her ikisi de senin ahbaplarına benzemiyorlar mı?" (Yurdatab, 1941: 9). Muhabbet devam ederken bir de bobstil şair ortaya çıkar. Tayyar'ın arkadaşlarından biri, 'gayet güzel 
bir 'poizi'm var.” diyerek konuşmaya dâhil olur. Poizi’nin ne olduğunu sorgulayan Nasrettin Hoca'ya "şiir" cevabı verilir. Edip Hepatar adlı şair genç, cebinden çıkardığg bir tomar kâğıdı eline alarak şiir okumaya başlar. Nasrettin Hoca, anlamdan ve âhenkten yoksun şiir karşısında: "Bu genç yaşında aklını kaçırmış, abuk sabuk konuşuyor, bir de buna şiir diyor..” diyerek bu tarz şiirlerden kendisinin de söyleyebileceğini belirtir:

Ey Bobstil

Babanın ceketini annenden habersiz giydiğin için

Burnundan gelecek yarın

fitil.. fitil

Ey şair-i edip

Timarhaneye girip

ne zaman çıktın

Aman aman

sana çok benziyor

bizim komşu delioğlan

Şu zavallı kıza bakın

Tıpkı bir postacı gibi

sallanır çantası

Hele takunyas 1

takır tukur

gürültü çıkartır (Yurdatab, 1941: 12).

Nasrettin Hoca, bir anda aklına gelip okuduğu şiir ile bobstil gençlerin şiir anlayışlarını eleştirir. Böylelikle yeni şiirin emeksiz yazılabileceğini, duygudan ve manadan yoksun olduğunu hissettirir. Hikâye genel olarak değerlendirildiğinde ise Nasrettin Hoca'nın mizahından istifade edilerek geçmiş ile son nesil arasındaki zihniyet farklılığına dikkat çekildiği anlaşılır.

Hakkı Bigeç'in ve Selami Münir Yurdatap'ın kitapçıklarına ek olarak gazetelerde yayımlanan hikâyeler, bobstillerin belli başlı özelliklerine ve toplum nazarındaki değerlerine dikkat çeker. Hikmet Feridun Es'in "Torununun Nişanlısı” adlı hikâyesinde, Hamdi Bey ile bobstil torunu Orhan ve nişanlısı Yıldız arasındaki nesil çatışması anlatılır. Orhan ve Yıldız'ın “Amerikanvari” bir tarzda kendi aralarında nişanlanmaları, bobstil modaya uygun kıyafetleri Hamdi Bey tarafindan yadırganır (6 Ağustos 1940: 6).

Reşat Feyzi’nin kaleme aldığı "Bobstil Aşkı” hikâyesinde olay, bobstil gençlerin kısa bir bakış ve karşılıklı gülüşmeden sonra "azami on dakika içinde" sevgili olmaları, birlikte eğlenmeleri ve akşam olduğunda yeni bir sevgili ile yollarına devam etmeleri üzerine kuruludur (26 Birincikanun 1940: 4). Bobstil gençlerin dejenere hayatını yansıtan hikâyede, en dikkat çekici unsur onların aşk ve sevgi üzerine düşünceleridir. İçinde yetiştikleri kültüre yabancı olan, gelenekteki değerleri reddeden bobstiller, gerçek aşk ve sevgiye karşıdırlar; günlük yaşamanın, gündelik aşk ve sevgilerin peşinden giderler. 
C.K. müstearıyla yayımlanan "Bobstil Olmuşum" hikâyesi, bobstillerin kıyafetleri ve kadınların modaya düşkünlüklerini konu edinir. Hikâyenin kahramanı olan fakir genç, yeni kıyafet alamadığı için babasının eskilerini giyer. Kıyafetlerinden dolayı bir mecmua sayfasında “yeni usul delikanlı” başlığıyla resmini görür. Fakir genç, güya bobstil kıyafetler tercih ettiği için sevgilisi tarafından da taparcasına sevilir (17 Şubat 1941: 5).

Cemil Nejat'ın "Bereket Modaya” başlıklı hikâyesi, "Bobstil Aşkı” ve "Bobstil Olmuşum” hikâyeleriyle aynı konuyu işler. Hikâye kahramanı Ahmet Cemal yakışıklı, zengin, şık, titiz ve iyi huylu bir genç olmasına rağmen modayı takip etmediği için âşık olduğu Piraye tarafından karşılık bulamaz. İşleri bozulup geçim sıkıntısı çekmeye başlayınca kılık ve kıyafetine dikkat edemez, eski elbiselerini giymek zorunda kalır. Ancak keyfi yerindedir; zira Piraye evlilik teklifini kabul etmiş, "Benim bobstilim Cemalim" diyerek Ahmet Cemal'e sevgisini göstermiştir (9 İkincikanun 1941: 5).

Hikmet Feridun Es'in "Köpek” adlı hikâyesi, diğer metinlerde olduğu gibi bobstil gençlerin aşkını konu edinir. Kendisine eş arayan mahallenin güzel kızı Nimet, "vücudu Yunan heykellerini gölgede birakacak derecede güzel" olan ve Amerikan artistlerine benzeyen Ahmet adında gençle tanışır. Ahmet'in bobstil bir genç olması, Nimet'in onunla arkadaşlık kurmasının ve evlenmesinin tek nedenidir (11 Kânunusani 1941: 6).

Meziyet Hâmid Uraz'ın "Yurdumu ve Kadınımı Asla” adlı hikâyesi, bobstil gençlerin aşklarına karşı yazılmış bir metindir. Edebiyat ve sanatı seven, aile terbiyesiyle yetişmiş Filiz, vatanî görevini yapan Kenan’ı sever. Bir buçuk yıl Amerika'da yaşayıp bu süreçte kendi "benliğinden sıyrılmış", dış görünüşü ve zihniyeti itibariyle tam bir bobstil genç olan Kemal de Filiz'le evlenme niyetindedir. "Tesadüfî bir dedikodu meltemiyle bu vaziyeti” işiten Kenan, izin alarak gelir ve Filiz'i nikâhına alır. Hikâyenin ana fikri Kenan üzerinden şu cümleyle aktarılır: "Sanki iri siyah gözleri belki hayatta her şeyimi veririm. Fakat senin gibi dejenere olmuş bir insana, yurdumu ve kadınımı asla diye haykırıyordu" (20 Ekim 1945: 4). Bu cümleler, bobstillere karşı verilen mücadelenin hikâyeye yansımış hâlidir. Filiz, Ercüment Ekrem' in "Bobstil Şair” romanında yer alan Halkevi'ndeki gençleri, Yedek Subay Yavuz'u ve Teğmen Ali Bahtiyar’1 anımsatmaktadır.

\section{Sonuç}

Bobstil, Amerikan sinemasindaki Hollywood aktörlerinden Robert Taylor'un isminden esinlenerek bir kıyafet modası olarak 1940'lara damga vurmuştur. Bu modayı takip eden tipler; garip karşılanan kıyafetleri, yabancı sözcüklerle konuşma hevesleri, ahlakî zaafları, milli ve manevi değerlerden uzak şuursuzca yaşamları ile Osmanlı Devleti'nin Batılılaşma sürecinde karşılaş1lan alafranga züppenin Cumhuriyet devrindeki yeni bir görünümü olarak düşünülmüştür. Kök ve kimlik yoksunluğu noktasında ortak paydada toplanan bu tipler, örnek alınan medeniyete bağlı olarak geçmişte Fransız kültürüne ve diline; 1940'larda bobstillerle birlikte Amerikan kültürüne ve İngilizceye yönelmişlerdir.

Bobstil, her türlü yenilik ve farklılık manasını ihtiva eden anlam genişlemesiyle devrin edebiyat tartışmalarında kullanılan bir kelimedir. Garip Hareketi’ni oluşturan Orhan Veli, 
Oktay Rifat ve Melih Cevdet devrin geleneksel şiirini savunanlar tarafından "bobstil şair" yakıştırmasına maruz kalmışlardır. Âhenksiz ve manasız görülen şiirleri ise benzer şekilde "bobstil şiir" yakıştırması ile eleştirilmiştir. Giyim tarzı ve devri için farklılık gösteren şiirleriyle Asaf Halet Çelebi de "bobstil şair" yakıştırmasından nasibini almıştır. Ayrıca bobstil, devrin moda düşkünü gençlerini ihtiva eden manasıyla şiir diline de nüfuz etmiştir.

Bobstiller, gerçek hayattan edebî metinlere iki farklı şekilde aksetmişlerdir. Bunlardan biri, bobstil modayı takip etmekle birlikte sanatla iştigal eden şair tiplerdir. Geçmişteki şairleri, mevcut şiir dilini reddedip yeniyi aramaları, yeni bir şiir hareketi vücuda getirme istekleri, şiirlerinin saçma ve anlamsız karşılanması bu tipin belirgin özelliğidir. Ercüment Ekrem'in "Bobstil Şair" adlı romanı bahsi geçen tipin vasıflarını tespite imkân sağlamıştır. Edebî metinlerdeki bir diğer bobstil tip ise kıyafetleri, milli ve manevi değerlere yabancılığı ile toplumun züppe gençleridir. Hayatı eğlenceden ibaret görmeleri, şuursuzca hayat sürmeleri, sevgiye kıymet vermemeleri onların belirgin yönleridir. Vücudu ve dimağıyla Cumhuriyetin inkılâp nesli karşısında tehlike arz eden bobstiller, devrin aydınları tarafından eleştiri oklarının hedefi olmuşlardır. Edebi metinlerde ise bobstillerin karşısında dış görünüşleri itibariyle örnek teşkil eden, aynı zamanda Türklük şuuruna sahip, milli ve manevi değerlerini koruyan genç kahramanlar yer almıştır.

\section{Notlar}

1 "Bobstil Şair" romanındaki 22. tefrikada Safiye Hanım ile İskender Bey’in oğlu dünyaya gelir. Ercüment Ekrem, bu erkek çocuğu Orhan diye tanıtmıştır. Ancak 26. tefrikada bu ismi Turhan olarak değiştirmiştir.

2. Çalçene müstearı, Hisarcılar grubunun oluşumunu hazırlayan şair ve yazar Mehmet Nuri Çınarlı tarafından kullanılmıştır (Yıldırım, 2006:124).

\section{Kaynaklar}

[Ensondakika]. (25 Birinciteşrin 1940). Bir iki nokta: Bobstil tip, bobstil Şiir. En Son Dakika, ss. 2 [İsimsiz]. (18 Kânunuevvel 1940). Şefkati maskelemeli. Akşam, ss. 1.

[İsimsiz]. (Sonkanun 1941). Edebi hatıralar, fikralar. Yücel, S. 71, ss. 86. [İsimsiz], (17 Kânunuevvel 1940). Talebeler bobstil elbise giyemeyecek. Cumhuriyet, ss. 2.

A.N.K. (20 Birincikanun 1940). Bobstiller. Yeni Sabah, ss. 6.

Acar, M. (16 Birincikanun 1940). Bobstillere balta! En Son Dakika, ss. 3.

Adıvar, H. E. (12 Nisan 1944). Hüseyin Rahmi’nin eserleri arasında II. Akşam, ss. 3.

Akdemir, N. (1943). Bobstil kaynanaya maşallah ho ho ho. İstanbul: Kemal Özcan.

Alver, K. (2006). Züppelik anlatısı ve toplum: Türk romanında züppe tipi. Selçuk Üniversitesi FenEdebiyat Fakültesi Edebiyat Dergisi, S. 16, ss. 163-182.

Bigeç, H. (1941). Bobstil futbolcu. İstanbul: Milli Mecmua.

C. K. (17 Şubat 1941). Bobstilo! Tan, ss. 5.

Cantek, L. (Haziran 2001). Cumhuriyet Türkiyesi'nde modernliğin tekinsiz suretleri: Kadınlar, gençler ve bobstil. Birikim, S. 146, ss. 56-63.

Coşkun, N. S. (15 Birinciteşrin 1940). Bobstiller. Son Posta, ss. 7. 
Çağbayır, Y. (2017). Ötüken Türkçe sözlük 1. İstanbul: Ötüken.

Çalçene. (25 Haziran 1944). Karagöz küllük şairi. Yeni Sabah, ss. 2.

Çimdik. (25 Şubat 1943). İstemezük. Akbaba, S. 455, ss. 5.

Es, H. F. (6 Ağustos 1940). Torunumun nişanlısı. Akşam, ss. 6.

Es, H. F. (17 Ağustos 1940). Bir çırpıda: Bobstil edebiyat. Akşam, ss. 3.

Es, H. F. (11 Kânunusani 1941). Köpek. Akşam, ss. 6.

Femik, F. (18 Aralık 1940). Bobstil düşkünlerinin hali. Vatan, ss. 6.

Feyzi, R. (19 Birincikanun 1940). Bobstil şair. Son Telgraf, ss. 4.

Feyzi, R. (26 Birincikanun 1940). Bobstil aşk1. Son Telgraf, ss. 4.

Gariboğlu, F. (İkinciteşrin 1940). Bobstil. Akbaba. S. 357, ss. 5-6.

Gençosman, K. Z. (14 Aralık 1940). Günün gölgesi: Bobstil kimdir? Ulus, ss. 2.

Gülendam, R. (2009). Asıl “Garip”: Âsaf Hâlet Çelebi. Turkish Studies, 4(1-2), ss. 1179-1201.

Irgat, C. S. (19 Birincikanun 1942). Bobstil şiirler. Çınaraltı, S. 65, s. 112.

İlhan, A. (1 Temmuz 1954). Sosyal realizmin münasebetleri yahut başlangıç. Mavi, S. 21, ss. 1-2.

İntepe, K. (2 Aralık 1942). Bobstil! Türk Yurdu, S. 1021, ss. 2.

Kanık, O. V. (1982). Bütün şiirleri. İstanbul: Can.

Karay, R. H. (12 Haziran 1941). Hafta konuşması: (Didon)dan (Naylon)a kadar. Akşam, ss. 2.

Kezege. (8 Şubat 1941). Seni gidi, bobstil... Sensin, ağzını topla! Ulus, ss. 2.

Koçu, R. E. (1967). Türk giyim kuşam ve süslenme sözlüğü. Ankara: Sümerbank.

Münir, H. (15 İkincikânun 1941). Günden güne: Yeni bir hareket mefhumu. Vakit, ss. 3.

Narlıkaya, F. F. (21 Ağustos 1941). Eski Paris modası ve bobstiller, İkdam, ss. 4.

Nejat, C. (9 İkincikanun 1941). Bereket modaya. Vakit, ss. 5.

Nureddin, V. (3 Nisan 1941). "Bobstil" ve "Süleyman Efendi”. Akşam, ss. 3.

Nureddin, V. (6 Temmuz 1940). Akşamdan akşama: Bobstil. Akşam, ss. 3.

Orhon, O. S. (27 Mart 1941). Edebiyat sohbeti. Akbaba, S. 375, ss. 4-5.

Özgül, M. K. (2018). Dîvan Yolu'ndan Pera'ya selâmetle modern Türk şiirine doğru. İstanbul: Yap1 Kredi.

Rado, Ş. (8 Eylül 1943). Sözün gelişi: Zavallı peder! Akşam, ss. 2.

Sağnak, R. F. (14 Haziran 1941). Sırası düştükçe: Bop-stil. Türk Dili, ss. 1.

Sazyek, H. (1996). Cumhuriyet dönemi Türk şiirinde garip hareketi. İstanbul: Türkiye İş Bankası.

Talu, E. E. (20 Birincikanun 1940). Sözün kısası: Maarif ve bobstiller. Son Posta, ss. 2.

Talu, E. E. (22 Eylül 1942). Bobstil Şair- 22. Anadolu, ss. 2.

Talu, E. E. (26 Eylül 1942). Bobstil Şair- 26. Anadolu, ss. 2.

Talu, E. E. (27 Eylül 1942). Bobstil Şair- 27. Anadolu, ss. 2.

Talu, E. E. (28 Eylül 1942). Bobstil Şair- 28. Anadolu, ss. 2.

Talu, E. E. (29 Eylül 1942). Bobstil Şair- 29. Anadolu, ss. 2.

Tevfik, N. (2009). Azâb-ı mukaddes. İ. Ada (Haz) İstanbul: Kap1.

Uraz, M. H. (20 Ekim 1945). Yurdumu ve kadınımı asla. Tanin, ss. 4.

Yıldırım, T. (2006). Edebiyatımızda müstear isimler. İstanbul: Selis.

Yurdatap, S. M. (1941). Nasrettin Hoca bobstiller arasında. İstanbul: Yeni Mecmua.

Yücebaş, H. (1976). Hiciv ve mizah edebiyatı antolojisi. İstanbul: Milliyet. 